\title{
Spatial distribution and controlling factors of stable isotopes in meteoric waters on the Tibetan Plateau: implications for paleoelevation reconstruction
}

Lin $\mathrm{Li}^{*}{ }^{\dagger}$, Carmala N. Garzione

\begin{abstract}
Debates persist about the interpretations of stable isotope based proxies for the surface uplift of the central-northern Tibetan Plateau. These disputes arise from the uncertain relationship between elevation and the $\delta^{18} \mathrm{O}$ values of meteoric waters, based on modern patterns of isotopes in precipitation and surface waters. We present a large river water data set (1,340 samples) covering most parts of the Tibetan Plateau to characterize the spatial variability and controlling factors of their isotopic compositions. Compared with the amount-weighted mean annual oxygen isotopic values of precipitation, we conclude that river water is a good substitute for isotopic studies of precipitation in the high flat (e.g., elevation $>3,300 \mathrm{~m}$ ) interior of the Tibetan Plateau in the mean annual timescale. We construct, for the first time based on field data, contour maps of isotopic variations of meteoric waters $\left(\delta^{18} \mathrm{O}, \delta \mathrm{D}\right.$ and $\mathrm{d}$ excess) on the Tibetan Plateau. In the marginal mountainous regions of the Plateau,
\end{abstract}


25 especially the southern through eastern margins, the $\delta^{18} \mathrm{O}$ and $\delta \mathrm{D}$ values of river 26 waters decrease with increasing mean catchment elevation, which can be modeled as 27 a Rayleigh distillation process. However, in the interior of the Plateau (north of $2830^{\circ} \mathrm{N} /$ Trans-Himalaya range), northward increasing trends in $\delta^{18} \mathrm{O}$ and $\delta \mathrm{D}$ values are 29 pronounced and present robust linear relations; d-excess values are lower than the 30 marginal regions and exhibit distinct contrasts between the eastern $(8 \%-12 \%)$ and 31 western $(<8 \%)$ Plateau. We suggest that these isotopic features of river waters in the 32 interior of the Tibetan Plateau result from the combined effects of: 1) mixing of 33 different moisture sources transported by the South Asian monsoon and Westerly 34 winds; 2) contribution of moisture from recycled surface water; and 3) sub-cloud 35 evaporation. We further provide a sub-cloud evaporation modified Rayleigh 36 distillation and mixing model to simulate the isotopic variations in the western Plateau. 37 Results of this work suggest that stable isotope-based paleoaltimetry studies are 38 reliable in the southern through eastern Plateau margins; towards the central-northern 39 Plateau, this method cannot be applied without additional constraints and/or large 40 uncertainties.

42 Key words: Tibetan Plateau, river water, stable isotope, paleoaltimetry, sub-cloud 43 evaporation, back trajectory analysis 


\section{Introduction}

(1)

Observations that the isotopic values $\left(\delta^{18} \mathrm{O}\right.$ and $\left.\delta \mathrm{D}\right)$ of meteoric waters (e.g., precipitation and river water) decrease with increasing elevation (Dansgaard, 1964; Garzione et al., 2000b; Gonfiantini et al., 2001; Poage and Chamberlain, 2001; Rozanski et al., 1993) and that authigenic carbonates can preserve the isotopic composition $\left(\delta^{18} \mathrm{O}\right)$ of paleo-meteoric waters (Cerling and Quade, 1993; Hoke et al., 2009; Talbot, 1990), led to the application of stable isotope-based paleoaltimetry to reconstruct the surface uplift history of orogenic belts and plateaus (Chamberlain and Poage, 2000; Garzione et al., 2000a; Rowley et al., 2001). Applications of this method in the southern Tibetan Plateau yield consistent results between different researchers (e.g., Currie et al., 2005; Ding et al., 2014; Garzione et al., 2000a; Rowley et al., 2001; Saylor et al., 2009), that also agree well with other paleoelevation proxies, such as foliar physiognomy and clumped isotope studies (Huntington et al., 2014; Spicer et al., 2003). However, using the same method to interpret topographic growth in the central-northern Tibetan Plateau is debated. For example, paleoelevation estimations for the Eocene and Miocene east Hoh Xil basin could differ by more than 3,500 m and 4,000 m, respectively (Bershaw et al., 2012; Cyr et al., 2005; Polissar et al., 2009; Quade et al., 2011). To a large extent, these disputes arise from the uncertain relationship between elevations and $\delta^{18} \mathrm{O}$ values of meteoric waters associated with competing fractionation processes in this deep continental setting (Bershaw et al., 2012; Hren et al., 2009; Tian et al., 2007; Yao et al., 2013), which result in large deviations from the isotopic values predicted from a simple Rayleigh distillation process on which stable isotope-based paleoaltimetry is based (Rowley and Garzione, 2007; Rowley et al., 2001). 

water isotopes on the Tibetan Plateau. As a direct condensate from the atmosphere, precipitation is the most commonly used source for studying meteoric waters.

71 However, due to the limited and uneven distribution of monitoring stations on the

72 Tibetan Plateau (Fig. 1), precipitation is a less ideal object to study isotopic variations 73 on a plateau scale. In situations like this, surface waters, especially river water, may provide a reasonable substitute for precipitation. River water is mainly supplied by precipitation that infiltrates the groundwater table or flows overland. River water can capture the isotopic compositions of local precipitation (Kendall and Coplen, 2001; Rowley and Garzione, 2007). In addition to the fact that river waters are much easier to sample, their isotopic compositions represent the amount-weighted average value of precipitation in the upstream catchment area. If sampled outside of the main rainy season, the isotopic compositions of stream water reflect those of groundwater input. Although infiltration to groundwater might be biased to times when precipitation is greater than potential evaporation, it has been argued that the isotopic compositions of river water can provide an amount-weighted integration of annual precipitation,

84 information that is useful in constructing the elevation- $\delta^{18} \mathrm{O}$ relation for stable isotope-based paleoaltimetry studies (Rowley and Garzione, 2007). Plateau (Bershaw et al., 2012; Ding et al., 2009; Hren et al., 2009; Liu, 2014; Quade et al., 2011; Xu et al., 2014). These studies confirm the competing influence of the

89 South Asian monsoon and Westerly moisture sources (Hren et al., 2009), as well as 90 the important role of local surface water recycling (Bershaw et al., 2012). However, 91 large gaps in river water sampling from the western, central and eastern Plateau (Fig. 
1) leave challenges in interpreting the controlling factors for isotopic variations across the whole Tibetan Plateau region.

In this study, we carried out wide-spread sampling of river waters in parts of the Tibetan Plateau that still lack data (Fig. 1, red dots). In combination with previous published river water data (Bershaw et al., 2012; Ding et al., 2009; Hoke et al., 2014; Hren et al., 2009; Liu, 2014; Liu et al., 2014; Quade et al., 2011; Xu et al., 2014), this large data set improves our knowledge of the spatial variability of stable isotopic compositions of river waters on the Tibetan Plateau, and also allows us to address the following major questions: 1) Is river water a good substitute for precipitation to

101 study the spatial isotopic variations on the Tibetan Plateau on the mean annual

102 timescale? and 2) What are the controlling factors for isotopic variations of meteoric waters (river water/precipitation) on the Tibetan Plateau? We address the first

104 question through a comparison of river water data with available precipitation data,

105 and the second question by looking at the spatial variations of $\delta^{18} \mathrm{O}, \delta \mathrm{D}$ and d-excess

106 values. Finally, with this new understanding, we discuss the implications for stable isotope-based paleoaltimetry studies in the Tibetan Plateau.

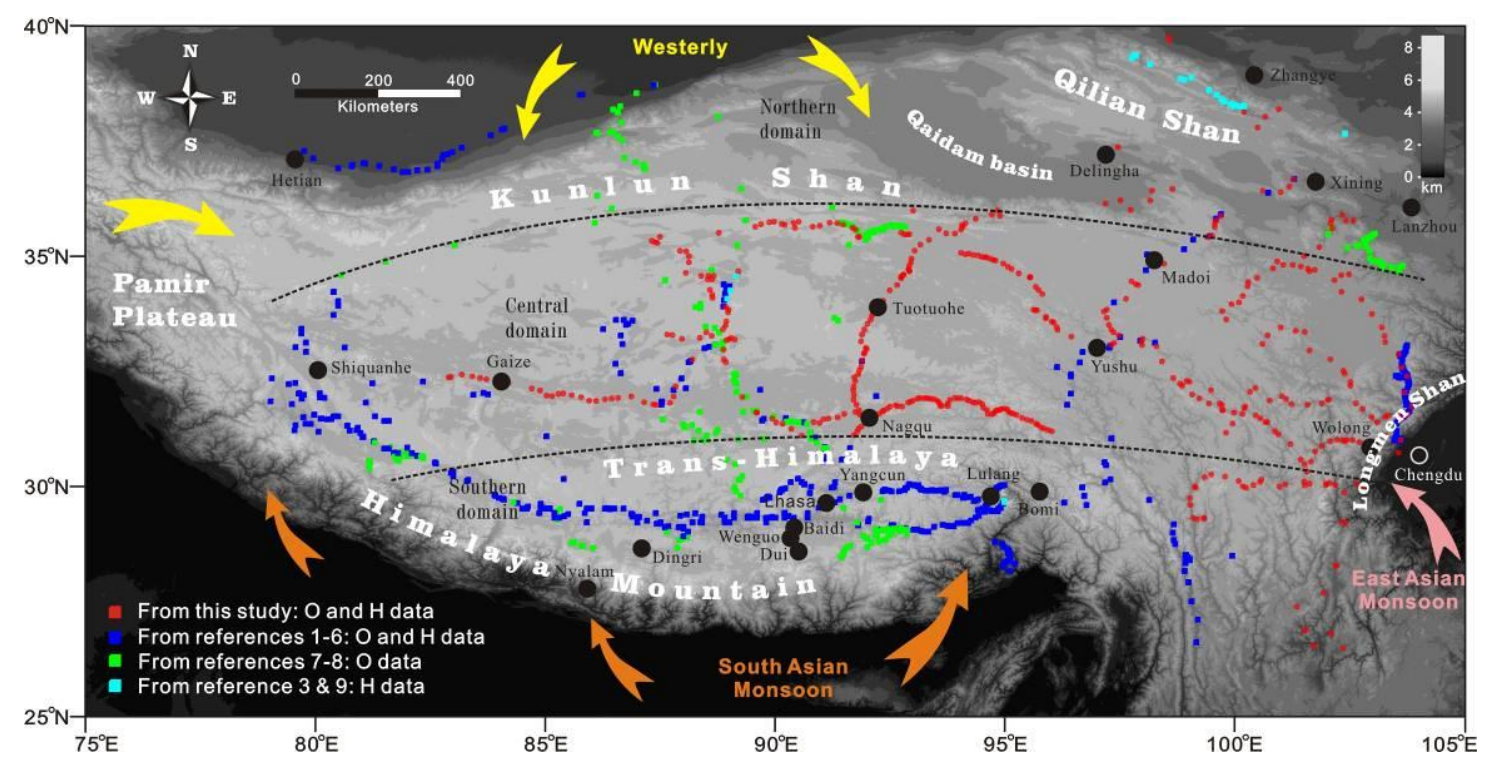

110 Red dots, from this study; Blue, green and cyan squares, from literature 1-9. Big thick arrows 
111 indicate major external air masses of the Tibetan Plateau (brown: South Asian monsoon; pink:

112 East Asian monsoon; yellow: Westerlies; Araguás-Araguás et al., 1998). Large white letters are

113 major mountain chains. Two east-west trending dashed lines are boundaries between three

114 isotopic domains (northern, central and southern; Yao et al., 2013). Large black dots are

115 precipitation monitoring stations. References: 1, Bershaw et al., 2012; 2, Hoke et al., 2014; 3,

116 Hren et al., 2009; 4, Liu, 2014; 5, Quade et al., 2011; 6, Xu et al., 2014; 7 Ding et al., 2009; 8,

117 Garzione et al., 2004; 9, Bai et al., 2012.

118

119 2. Geography and moisture transport

$120 \quad 2.1$ Geography

121 The Tibetan Plateau is the highest and largest topographic feature on Earth (Fig.

122 1). Except the northeast and southeast, all the other margins are bounded by very high

123 elevation $(>6,000 \mathrm{~m}$ ) and steeply sloped (gradients up to 6\%) mountain chains; such

124 as the Himalayan Mountains, Longmen Shan, and Kunlun Shan ("Shan" means

125 mountain in Chinese) (Fig. 1). The eastern Plateau (mainly east of $93^{\circ} \mathrm{E}$ ) is

126 characterized by rugged terranes, with high-discharge, south-southeastward flowing

127 rivers cutting deeply $(2,000-3,000 \mathrm{~m})$ into the landscape. On the contrary, the western

128 Plateau is relatively flat, with most regions between 4,500-5,000 m. Interestingly, this

129 east-west topographic difference is also accompanied by difference in annual

130 precipitation amount: high in the east $(>400 \mathrm{~mm} / \mathrm{year})$ and low in the west $(<400$

$131 \mathrm{~mm} /$ year) (Maussion et al., 2014).

132 The northern Plateau, represented by the Qaidam basin and Qilian Shan, is 133 relatively low elevation regions $(2,500-4,500 \mathrm{~m})$, and receives little precipitation. The

134 western-most Plateau, locally known as the Pamir Plateau, is also characterized by

135 rugged landscape (Fig. 1). Different from the other parts of the Tibetan Plateau, which

136 are dominated by summer precipitation (>80-90\% of annual precipitation amount),

137 the Pamir Plateau receives most of its precipitation during the winter season (Fig. 2). 


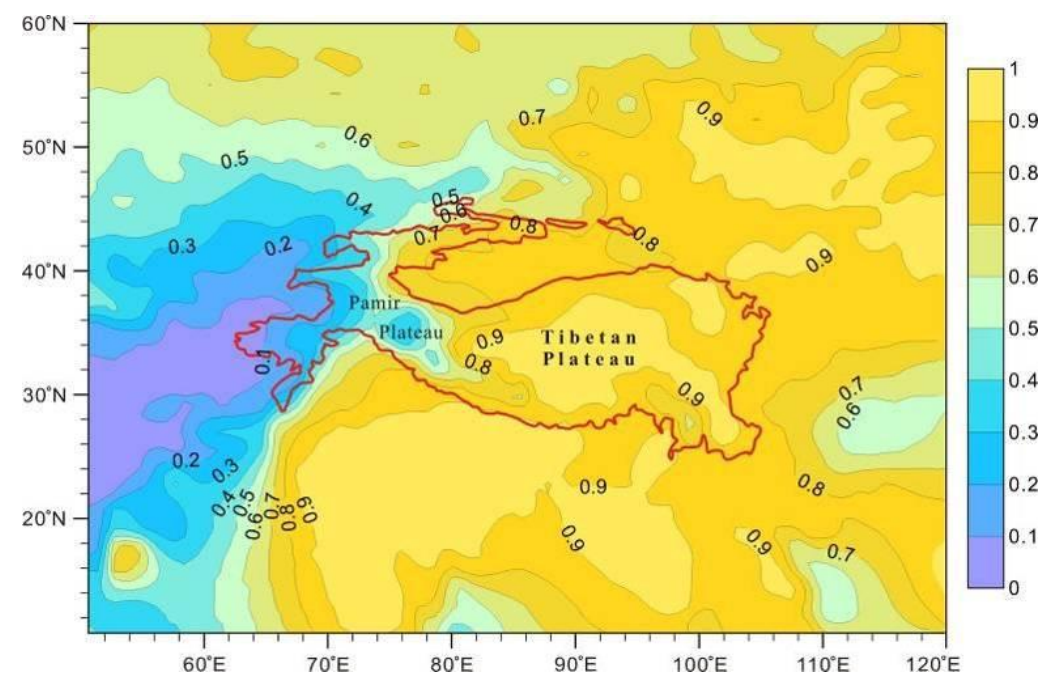

141 Fig. 2. Contour map of summer precipitation index, defined as the percentage of summer (May to

142 October) precipitation amount over annual precipitation amount (1980-2010). 0, all winter

143 precipitation; 1, all summer precipitation. Thick red outlines are the 2,000 m altitude contour of

144 the Tibetan Plateau and surrounding regions. Note that all the river water samples in this study are

145 located to the east of $79^{\circ} \mathrm{E}$ (Fig. 1), which are dominated by summer precipitation $(>80 \%)$.

146 Original precipitation data is from the NOAA Earth System Research Laboratory's GPCC full

147 data reanalysis V6 combined.

\subsection{Moisture origin and transport}

There are three main external sources providing moisture for precipitation on

151 the Tibetan Plateau, including the South Asian monsoon, mid-latitude Westerlies and

152 East Asian monsoon (Fig. 1) (Araguás-Araguás et al., 1998; Tian et al., 2007). The

153 first two provide the majority of moisture (Chen et al., 2012; Feng and Zhou, 2012),

154 whereas the latter one appears to be significant only at the eastern-most margin and 155 exerts little influence on the remaining Plateau (Curio et al., 2015).

Along the transport path of these air masses into the interior of the Tibetan

157 Plateau, high mountain chains on the margins (Fig. 1) block moisture from entering

158 the Plateau. A large amount of moisture is precipitated when forced to ascend over

159 high relief topography. River valleys that both parallel or cut through the mountain 
chains serve as the main channels for external moisture to penetrate the interior of the

161 Plateau, such as the Yarlung Tsangpo valley and Thakkhola graben in the Himalaya

162 Mountain and the Min and Dadu river valleys in the eastern Plateau. In the interior of the Tibetan Plateau, the relative significance of external

164 moisture, mainly the northward extension of the South Asian monsoon, is not well

165 constrained. Stable isotopic studies of precipitation (Tian et al., 2007; Yao et al., 2013)

166 suggest that regions south of $30^{\circ} \mathrm{N}$ are dominated by the South Asian monsoon (south

167 domain, Fig. 1); regions north of $35^{\circ} \mathrm{N}$ are dominated by Westerlies (north domain);

168 while regions in between are transitional between these two different moisture sources

169 (central domain).

170 3. Methods

$171 \quad 3.1$ River water sampling

172 The primary goal for sampling in this study is to cover parts of the Tibetan

173 Plateau that still lack river water data (Fig. 1). Ideally, river water samples should be

174 collected outside the main rainy season and the spring snowmelt season when rivers

175 show base-level flow that is representative of groundwater, the isotopic compositions

176 of which might reflect the amount-weighted mean annual precipitation composition.

177 Samples that lie to the east of $96^{\circ} \mathrm{E}$ were collected during the late spring and early

178 summer (May-early June) of 2012 and 2013, which is before the main rainy season

179 (middle June-early September). Samples were collected mostly from small (drainage 180 areas $<100 \mathrm{~km}^{2}$ ) and medium-sized rivers (100-1,000 km²; auxiliary Table S1). River

181 water samples in the west-central Plateau were collected in the late autumn (October182 middle November) of 2012 and 2013, which is the dry season. In this region, about $18360 \%$ samples are collected from small rivers or springs (auxiliary Table S1). 
185

186

187

188

189

190

191

192

193

194

195

196

197

198

199

200

201

202

203

204

205

\subsection{Isotope measurement}

All water samples were measured in the SIREAL stable isotope laboratory at the University of Rochester, using a liquid water isotope analyzer (model LWIA-24d) with a GC-PAL auto-sampler. For all water samples, at least two separate analyses were conducted for replication of results. Each analysis consists of 14 water injections, with a minimum of 7 injections, excluding the first 3 , required to calculate the isotopic composition. Analytical error is determined from the mean of multiple injections. Two in-house standards, both calibrated to Vienna Standard Mean Ocean Water (VSMOW) and Vienna Standard Light Antarctic Precipitation (VSLAP), were analyzed after every three samples for standardization. Isotopic results for both oxygen and hydrogen are reported using standard delta $(\delta)$ notation $(\%$, per mil) with respect to VSMOW, and analytical errors are better than $\pm 0.1 \%$ o $(1 \sigma)$ and $\pm 1.2 \%$ o $(1 \sigma)$, respectively.

\subsection{Data compilation}

The main criterion for use of river water data in this study is that they are representative of the isotopic composition of local meteoric water. We therefore exclude river waters that were sampled from very large trunk rivers because they capture rainfall isotopic signal over a very large drainage area $\left(>5,000 \mathrm{~km}^{2} ; 11\right.$ samples, auxiliary Table S1). In addition, we exclude river waters that exhibit either anomalous $\delta^{18} \mathrm{O}$ values $(>5 \%$, 2 samples) or anomalous d-excess values $(>5 \%$, 41 samples), compared with the average isotopic values of adjacent river waters within a $50 \mathrm{~km}$ radius (auxiliary Table $\mathrm{S} 1$ ).

In total, there are 1,340 river water samples used, including 458 newly collected and 882 compiled samples (Bai et al., 2012; Bershaw et al., 2012; Ding et al., 2009;

Garzione et al., 2004; Hoke et al., 2014; Hren et al., 2009; Liu, 2014; Quade et al., 
210 2011; Xu et al., 2014). In this data set, there are 1056 samples with both $\delta^{18} \mathrm{O}$ and $\delta \mathrm{D}$

211 values, 256 samples with only $\delta^{18} \mathrm{O}$ values, and 28 samples with only $\delta \mathrm{D}$ values.

$212 \quad 3.4$ Contouring of stable isotopic values

213 Based on the individual river water isotopic values, we construct the contour 214 maps of $\delta^{18} \mathrm{O}, \delta \mathrm{D}$ and d-excess values using Kriging gridding with linear variogram. 215 In this method, each grid node value is based on the known data points neighboring 216 the node; and each data point is weighted by its distance away from the node. This 217 gridding method can compensate for clustered data by giving less weight to the 218 cluster in the overall prediction.

219 We note that although Kriging gridding and contouring interpolated the isotopic 220 values in sparsely sampled regions, such as the Qaidam basin and the northwestern 221 Plateau (Fig. 1), they may be unreliable in these regions. This is also the case in most 222 of the Himalaya region, where samples are lacking and spatial isotopic changes are 223 very large associated with steep topographic gradients (Garzione et al., 2000b).

\subsection{HYSPLIT back trajectory analysis}

We use the HYbrid Single-Particle Lagrangian Integrated Trajectory Model (HYSPLIT) (Draxler and Rolph, 2013) to track air parcel trajectories in four locations in the western Plateau $\left(29.5^{\circ} \mathrm{N}, 88.0^{\circ} \mathrm{E} ; 32.5^{\circ} \mathrm{N}, 86.0^{\circ} \mathrm{E} ; 32.5^{\circ} \mathrm{N}, 90.0^{\circ} \mathrm{E} ; 35.0^{\circ} \mathrm{N}\right.$, 88. $\left.0^{\circ} \mathrm{E}\right)$. Meteorological parameters are from NCEP/NCAR reanalysis data

229 (Kanamitsu et al., 2002). For each of the four locations, 72-hour back trajectories 230 were computed every 12 hours for the months of June, July and August from 2010 to 2312013 , during the years in which new river water samples were collected. These three 232 months are chosen because they reflect the main rainy season on the Tibetan Plateau, 233 which accounts for more than $70 \%$ of annual precipitation (Fig. 2). The initial parcel 234 was set at $1 \mathrm{~km}$ above ground level, because most moisture in the atmosphere is in the 
235 lower troposphere, within 0-2 km above ground. We note that there is no apparent 236 difference in results for initiation elevations at $0.5,1.0$ and $1.5 \mathrm{~km}$ above ground level.

237 For each location, there are 736 back trajectories; however, because the HYSPLIT 238 back trajectory analysis deals with air parcels, and not vapor flux, we only consider 239 precipitation-producing trajectories, which are considered as yielding precipitation 240 within twelve hours before arriving at the location. We compile the end points of 241 precipitation-producing back trajectories and contour them based on their spatial 242 density. We also merge back trajectories that are near each other into clusters that are 243 represented by their mean trajectory.

244 4. Results and interpretations

245 River water samples used in this study were collected during different months 246 and years. In the eastern Plateau, Bershaw et al. (2012) collected samples in August of 247 2008, which is near the end of the rainy season. We collected samples along the same 248 N-S transect as Bershaw et al. (2012) in early May of 2012, before the rainy season. 249 Isotopic values of these two data sets are nearly identical (within $0.5 \%$ difference). 250 This is also the case (similar isotopic values between different data sets regardless of 251 the month of sampling) in the west-central Plateau. Given that the rainy season 252 provides $>80 \%$ precipitation of total annual precipitation on the Tibetan Plateau (Fig. 253 2), we infer that both the groundwater and river water are dominated by the isotopic 254 composition of rainy season precipitation.

$255 \quad 4.1 \delta^{18} \mathrm{O}$ and $\delta \mathrm{D}$ values and local meteoric water lines

256 The $\delta^{18} \mathrm{O}$ values of river waters across the Tibetan Plateau range between $257-20.8 \%$ and $-3.4 \%$, and the $\delta \mathrm{D}$ values range between $-165 \%$ and $-19 \%$ (Fig. 3, see 258 auxiliary Table S1 for all the isotopic data). The local meteoric water line of Tibetan 259 river water is $\delta \mathrm{D}=(8.55 \pm 0.05)^{*} \delta^{18} \mathrm{O}+(16.53 \pm 0.67)\left(\mathrm{R}^{2}=0.97, \mathrm{n}=1,056\right)$, which is 
steeper than the Southeast Asian precipitation line (including the Tibet area):

$261 \delta \mathrm{D}=7.92 * \delta^{18} \mathrm{O}+9.20$ (Araguás-Araguás et al., 1998). Fig. 3 also shows the local lake

262 water line of the Tibetan Plateau: $\delta \mathrm{D}=(6.40 \pm 0.24) * \delta^{18} \mathrm{O}-(24.37 \pm 1.74), \quad\left(\mathrm{R}^{2}=0.85\right.$, $263 \mathrm{n}=121$; for data, see auxiliary Table S2). The lower slope of the lake water line can be 264 attributed to non-equilibrium (kinetic) evaporative fractionation between lake water 265 and water vapor (e.g., Gonfiantini, 1986). The majority of river water values plot on a 266 line of steeper slope compared to the lake water line, suggesting insignificant surface 267 water evaporation, compared with the strong evaporation of lake water.

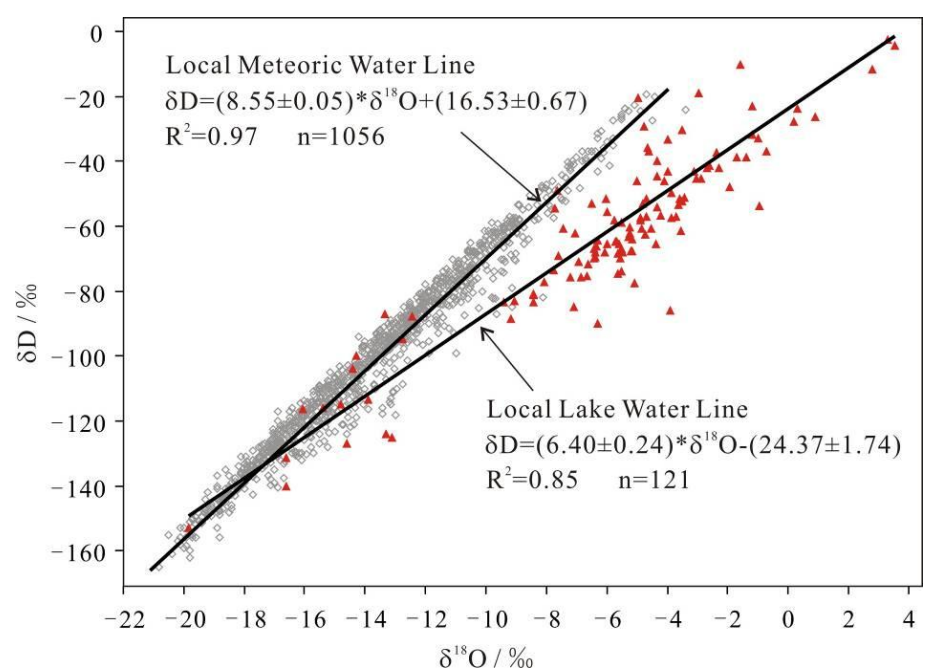

269 Fig. 3. $\delta \mathrm{D}-\delta^{18} \mathrm{O}$ relationship of river waters (grey open diamonds) and lake waters (red solid triangles) on the Tibetan Plateau. Also shown are the local meteoric water line and local lake water line.

Following Yao et al. (2013)'s division of the Tibetan Plateau into three domains 274 (Fig. 1), the local meteoric water lines for the northern, central and southern domains are: $\delta \mathrm{D}=(8.42 \pm 0.20) * \delta^{18} \mathrm{O}+(17.20 \pm 1.65) \quad\left(\mathrm{R}^{2}=0.97, \mathrm{n}=67\right), \quad \delta \mathrm{D}=(8.32 \pm 0.10) * \delta^{18} \mathrm{O}+$ $(12.83 \pm 1.26)\left(\mathrm{R}^{2}=0.93, \mathrm{n}=615\right)$, and $\delta \mathrm{D}=(8.89 \pm 0.06) * \delta^{18} \mathrm{O}+(23.02 \pm 1.02)\left(\mathrm{R}^{2}=0.98\right.$, $\mathrm{n}=374$ ), respectively. The central domain can be further divided into the western

278 (internally drained) and eastern (externally drained) parts (roughly along the $93^{\circ} \mathrm{E}$ ), 279 and the water lines for these two parts are $\delta \mathrm{D}=(7.91 \pm 0.15)^{*} \delta^{18} \mathrm{O}+(4.09 \pm 1.97)$ 
$\left(\mathrm{R}^{2}=0.91, \quad \mathrm{n}=277\right), \quad$ and $\quad \delta \mathrm{D}=(8.46 \pm 0.07) * \delta^{18} \mathrm{O}+(17.26 \pm 0.93) \quad\left(\mathrm{R}^{2}=0.98, \quad \mathrm{n}=338\right)$,

281 respectively. We note that the slopes of meteoric water lines in the northern and 282 central domains are lower ( 0.47 and 0.57 respectively) than that in the southern 283 domain, which is also the case for the western central domain (0.55 lower), compared 284 with that in the eastern central domain. Lower slopes suggest a stronger influence 285 from evaporation, which we interpret as stronger sub-cloud evaporation (discussed in 286 detail in section 6.2.3).

\subsection{Spatial distribution of $\delta^{18} \mathrm{O}$ and $\delta \mathrm{D}$ values}

The spatial distribution of individual $\delta^{18} \mathrm{O}$ and $\delta \mathrm{D}$ values of river waters and 289 corresponding contour maps are presented in Fig. 4A-B and C-D, respectively (also 290 auxiliary kmz file S1). We do not display the contour lines in the Himalaya Mountain 291 (white regions in Fig. 4C-D) due to the lack of samples (Fig. 1). The Kriging gridding method results in contours that are inconsistent with observed patterns along well-

293 sampled transects in this region (Bai et al., 2015; Garzione et al., 2000b; Quade et al., 294 2011). On the contrary, in the eastern margin (Longmen Shan), where there are a lot 295 of data (Fig. 1), the contours reflect theoretical predictions from Rayleigh distillation.
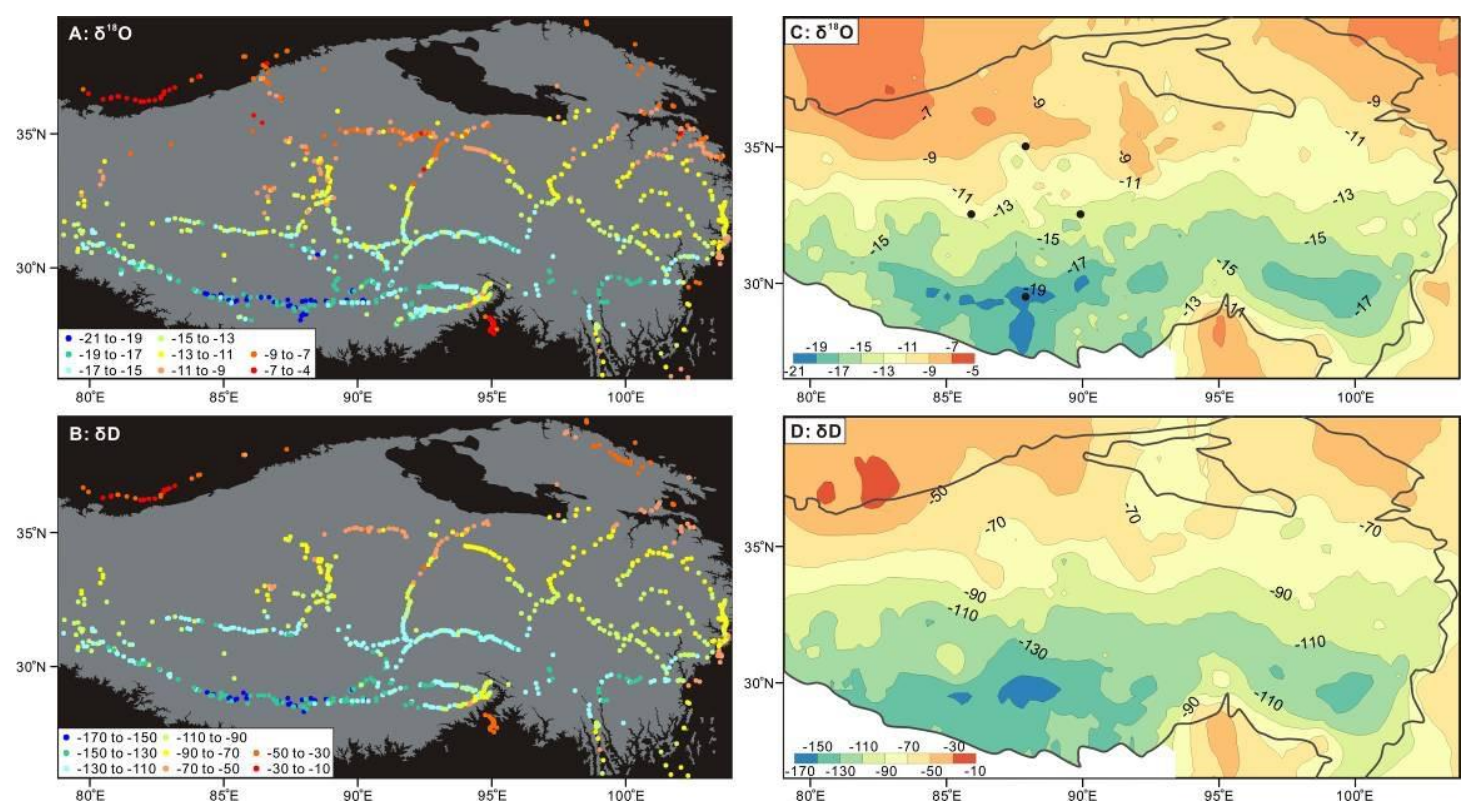
Fig. 4. A and B: 3,000 m altitude contour map (grey shades) of the Tibetan Plateau with locations 298 of river water samples, that are color coded by $\delta^{18} \mathrm{O}(\mathrm{A})$ and $\delta \mathrm{D}(\mathrm{B})$ values. Note that the samples 299 used for these two isotopes are slightly different (see section 3.3). $\mathbf{C}$ and $\mathbf{D}$ : Contour maps of $\delta^{18} \mathrm{O}$ 300 (C) and $\delta \mathrm{D}(\mathrm{D})$ values of river waters on the Tibetan Plateau. The thick dark grey lines are 3,000 $301 \mathrm{~m}$ altitude contours. The four black dots in $\mathrm{C}$ show locations for back trajectory analysis (see 302 section 6.2.1 and Fig. 8). Plateau decrease with increasing elevation; for example, along the southern slope of the Himalaya (Fig. 5A) and the eastern slope of the Longmen Shan (Fig. 5B). This trend is less apparent in the northern slopes of the Qilian Shan and West Kunlun Shan. In the central and northern Plateau, there is a pronounced northward increase in the $\delta^{18} \mathrm{O}$ values (from $\sim-18 \%$ o to $<-7 \%$ ). This trend reflects a linear relationship between latitude $\left({ }^{\circ} \mathrm{N}\right)$ and $\delta^{18} \mathrm{O}$ values $(\%): \delta^{18} \mathrm{O}=(1.13 \pm 0.03) *$ Lat-(49.78 \pm 0.85$)\left(\mathrm{R}^{2}=0.61\right.$,

$311 \mathrm{n}=1176$, Fig. 5E). The strength of the correlation improves when focusing on three

312 north-south transects in the eastern $\left(\sim 96-98^{\circ} \mathrm{E}\right)$, middle $\left(\sim 92-93^{\circ} \mathrm{E}\right)$ and western $313\left(\sim 88-89^{\circ} \mathrm{E}\right)$ Plateau $\left(\mathrm{R}^{2}=0.84,0.85\right.$ and 0.84 , respectively). No correlations between 314 longitude and $\delta^{18} \mathrm{O}$ values are found.

\section{$315 \quad 4.3$ Spatial distribution of d-excess values}

316 The $\mathrm{d}$-excess value ( $\mathrm{d}$-excess $=\delta \mathrm{D}-8^{*} \delta^{18} \mathrm{O}$ ) of meteoric water reveals the 317 difference in kinetic fractionation between $\mathrm{HD}^{16} \mathrm{O} / \mathrm{HH}^{18} \mathrm{O}$ and $\mathrm{HH}^{16} \mathrm{O}$ during phase 318 change under conditions where relative humidity is <100\% (Dansgaard, 1964; 319 Froehlich et al., 2008). The spatial distributions of d-excess values of river waters and 320 their corresponding contour map are presented in Fig. 6A-B (also auxiliary kmz file 321 S1). 

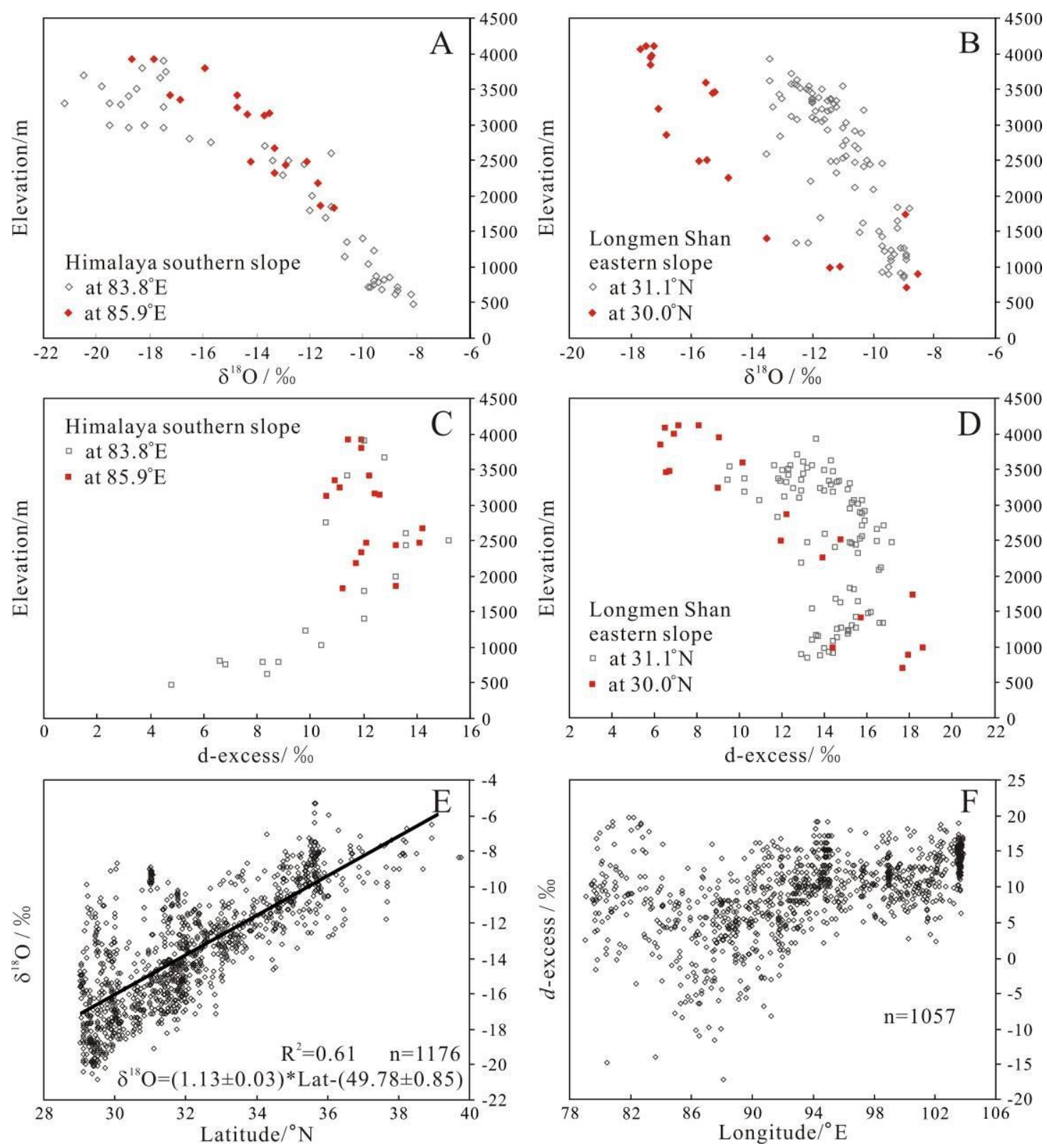

324 Fig. 5. Plots of $\delta^{18}$ O-elevation $(\mathbf{A}$ and $\mathbf{B})$ and d-excess-elevation $(\mathbf{C}$ and $\mathbf{D})$ variations at four 325 different transects in the southern Plateau Himalaya Mountain and eastern Plateau Longmen Shan.

326 Note that for the Himalaya southern slope at $83.8^{\circ} \mathrm{E}$, there are fewer data points for the d-excess plot compared with the $\delta^{18} \mathrm{O}$ plot, due to lack of availability of $\delta \mathrm{D} / \mathrm{d}$-excess values. Data sources:

328 Himalaya southern slope: at $83.8^{\circ} \mathrm{E}$, Garzione et al., 2000b; at $85.9^{\circ} \mathrm{E}$, Bai et al., 2015; Longmen 329 Shan eastern slope: at $31.1^{\circ} \mathrm{N}$, Xu et al., 2014; at $30.0^{\circ} \mathrm{N}$, this study. $\mathbf{E}$ and $\mathbf{F}$, plots of $\delta^{18} \mathrm{O}-$ 330 latitude $(\mathrm{E})$ and d-excess-longitude $(\mathrm{F})$ variations for river water samples on the Tibetan Plateau.

Generally, the d-excess values range between $-12 \%$ o to $20 \%$. We group their 333 spatial variations into three groups: 1) very high d-excess values between $12 \%$ and 
$33420 \%$ in the marginal high mountains of the Tibetan Plateau (Fig. 6B), which show 335 various trends (increase, decrease or remaining nearly the same) with increasing 336 elevation (Fig. 5C-D). In the interior of the Plateau, two sub-regions can be clearly 337 identified: 2) low d-excess values between $-12 \%$ and $8 \%$ in the western Plateau; and 3383 ) relatively high values $(8 \%-12 \%)$ in the eastern Plateau (Fig. 5F and 6B).

339 Although the dominant river size is medium (59\%) in the eastern Plateau and 340 small $(58 \%)$ in the western Plateau, we argue that the east-west contrast in d-excess 341 values is not a result of sampling bias. Comparing any group (e.g., large, medium or 342 small) of river water data, the d-excess values in the western Plateau are $\sim 9 \%$ lower 343 than rivers of similar size in the east, For example, comparing the d-excess values of 344 medium-sized rivers $(1.4 \%)$ in the western Plateau with the average values of all 345 samples $(10.3 \%$ ) in the eastern Plateau (dominated by medium sized rivers), there is a $346 \sim 9 \%$ difference between the east and west. 41 samples are excluded as a result of 347 anomalous d-excess values (auxiliary Table S1), although inclusion of these data does 348 not change the observation of the large contrast in d-excess values between the 349 eastern and western Plateau.
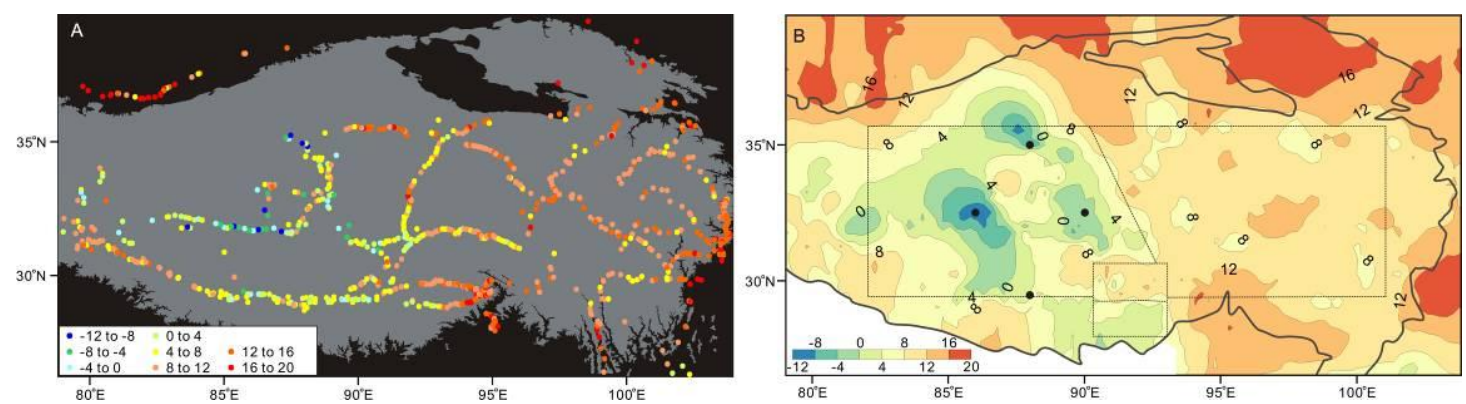

351 Fig. 6. A: 3,000 m altitude contour map (grey shades) of the Tibetan Plateau with locations of 352 river water samples that are color coded by d-excess values. B: Contour maps of d-excess values 353 of river waters on the Tibetan Plateau. The thick dark grey lines are 3,000 $\mathrm{m}$ altitude contours. The 354 four black dots in B show locations for back trajectory analysis (see section 6.2.1 and Fig. 8). The 355 black dotted boxes show areas with large d-excess differences in the interior of the Plateau. 


\section{Validity of river water as a substitute for isotopic studies of precipitation}

As most of the $\delta \mathrm{D} / \mathrm{d}$-excess values of precipitation on the Tibetan Plateau are

not reported in previous studies (e.g., Liu et al., 2008; Yao et al., 2013), we compare

360 the oxygen isotopic composition to assess the validity of using river water as

361 representative of the amount-weighted mean annual isotopic composition of

362 precipitation (Fig. 7 and auxiliary Table S3). On the plateau scale, the mean annual

363 oxygen isotopic value of precipitation increases from $~-18 \%$ in the south (e.g. station

364 Dui) to $\sim-7 \%$ in the north (e.g. station Zhangye). A linear relationship between the

$365 \delta^{18} \mathrm{O}$ values of precipitation and latitude also exists: $\delta^{18} \mathrm{O}=(0.96 \pm 0.17) *$ Lat-

$366(43.47 \pm 5.35)\left(\mathrm{R}^{2}=0.63, \mathrm{n}=22\right)$, which is very close to that of river water (Fig. 5E).

367 We compare the mean annual $\delta^{18} \mathrm{O}$ values of precipitation with the river water

$368 \delta^{18} \mathrm{O}$ contour in which the precipitation station falls. Among the 22 stations (Fig. 7

369 and auxiliary Table S3), there are 12 (stations 1-12) that show good agreement

370 (within $\pm 1 \%$ ) between the $\delta^{18} \mathrm{O}$ values of precipitation and the surrounding river

371 water contour. If only consider the 14 high elevation stations $(>3,300 \mathrm{~m}), 10$ of them

372 show good agreement. The 8 stations that lie in the piedmont lowland regions

373 (stations 15-22) show higher $\delta^{18} \mathrm{O}$ values than adjacent river water. The lower $\delta^{18} \mathrm{O}$

374 values of the river water likely reflect the integration of isotopic signals of

375 precipitation that fell in the much higher elevation catchment areas $(>1,000 \mathrm{~m}$

376 elevation difference, auxiliary Table S3). There are only two stations (stations 13-14)

377 that show lower $\delta^{18} \mathrm{O}$ values than the contour defined by river water data, which

378 suggests that the local river water may have experienced evaporation. 


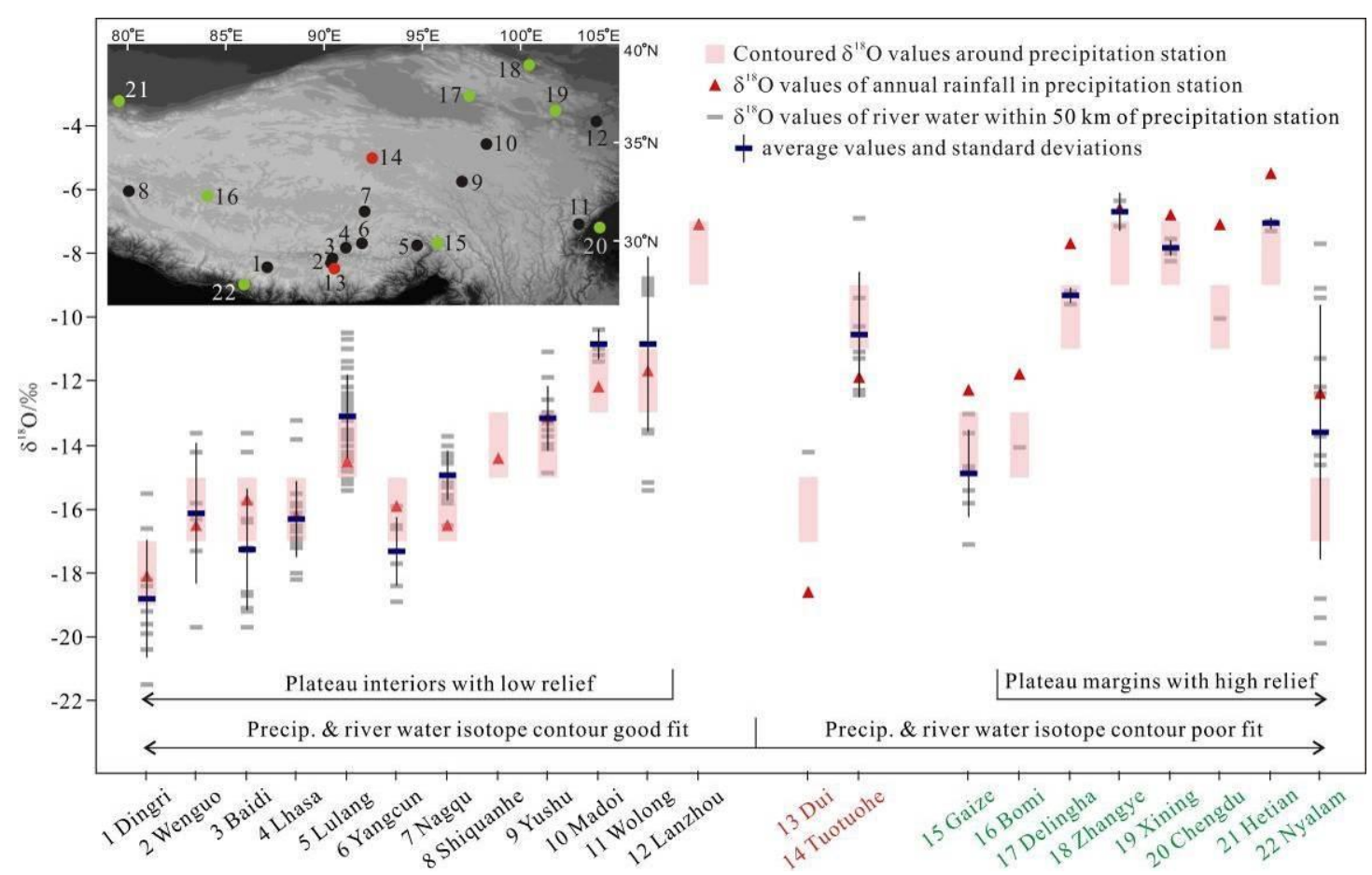

380 Fig. 7. Comparisons between the $\delta^{18} \mathrm{O}$ values of amount-weighted mean annual precipitation in 22 381 monitoring stations (red triangles), individual river waters (grey bars) and their average values 382 (blue bars with vertical lines) within $50 \mathrm{~km}$ radius of monitoring station, and contoured $\delta^{18} \mathrm{O}$ 383 values around monitoring station (pink vertical bands). Inset: Geographic locations of 384 precipitation observation stations (dots) on the Tibetan Plateau. The color codes indicate contoured $\delta^{18} \mathrm{O}$ values of river water that are in agreement with (black), or higher (red), or lower (green) than the mean annual $\delta^{18} \mathrm{O}$ values of precipitation.

Plateau is not significant. First, most of the river water data points fall to the left of the local lake water line, and only a few of them are located to the right of the line

391 (Fig, 2), suggesting a small percentage of the water samples experienced surface water evaporation. Second, comparison of the $\delta^{18} \mathrm{O}$ values of river water with 393 precipitation stations shows that most of the precipitation values agree with adjacent 394 river water values, especially in the high flat interior of the Plateau, with only 2 out 14 395 of the sites suggesting possible evaporation from river water (Fig. 7). Due to the lack of availability of $\delta \mathrm{D}$ and d-excess values of precipitation, we can not completely rule 
out the possibility of some degree of surface water evaporation and/or sublimation of snow that contribute to the $\delta^{18} \mathrm{O}$ signals of river waters in this region. However, it

399 should be insignificant, considering the small difference in $\delta^{18} \mathrm{O}$ values of river water 400 with precipitation.

401 The comparable nature of $\delta^{18} \mathrm{O}$ values of river water and precipitation, and the 402 lack of evidence of significant surface water evaporation indicate that river water is a 403 good substitute for the amount-weighted mean annual isotopic composition of 404 precipitation in the high flat interior (elevation $>3,300 \mathrm{~m}$ ) of the Tibetan Plateau.

405 6. Controls on the spatial isotopic variations of river water

\section{6.1 Margins of the Tibetan Plateau}

At the margins of the Tibetan Plateau, especially the southern and eastern margins (windward slopes of the Himalaya and Longmen Shan, Fig. 1), the $\delta^{18} \mathrm{O}$

409 values of river waters decrease with increasing elevation (Fig. 5A-B). The d-excess 410 values show differing trends in different locations; they either increase, or decrease, or 411 are more complex (Fig. 5C-D) with increasing elevation. Decreasing $\delta^{18} \mathrm{O}$ values 412 with increasing elevation is a typical feature of the altitude effect of meteoric waters 413 (Dansgaard, 1964; Rozanski et al., 1993). Early studies tended to consider d-excess 414 values to be unchangeable after moisture evaporated from the ocean surface (Craig 415 and Gordon, 1965; Merlivat and Jouzel, 1979). However, later model simulations 416 following a Rayleigh distillation process show that the d-excess values of 417 precipitation can either increase or decrease, due to the differences in relative 418 humidity and temperature during precipitation (Gonfiantini et al., 2001; Jouzel and 419 Merlivat, 1984). We consider the Rayleigh distillation process a reasonable fractionation 421 mechanism to account for the isotopic variations of river waters at the southern 
through eastern margins of the Tibetan Plateau (See Bershaw et al. (2012) for

423 Rayleigh distillation simulation in the Himalaya Mountains). We note that in the 424 northern mountainous margins (Kunlun Shan and Qilian Shan, Fig. 1), the Rayleigh 425 distillation process alone cannot explain the observed isotopic variations. Although 426 there is still a decreasing trend in the $\delta^{18} \mathrm{O}$ values of river waters with increasing 427 elevation, this altitudinal isotopic gradient is greatly damped to $\sim-1 \% \mathrm{~km}$, compared 428 with $\sim-3 \% / \mathrm{km}$ on the other margins, indicating that other fractionation mechanisms 429 (e.g., addition of recycled surface water and sub-cloud evaporation) are required to 430 account for the low $\delta^{18} \mathrm{O}$ versus altitude gradient.

\section{$431 \quad 6.2$ Interior of the Tibetan Plateau}

\subsubsection{Different moisture sources}

There are three external sources providing moisture for precipitation on the

434 Tibetan Plateau: the South Asian monsoon, the Westerlies, and the East Asian 435 monsoon (Fig. 1; Araguás-Araguás et al., 1998). The $\delta^{18} \mathrm{O}$ patterns of surface waters 436 in the eastern Plateau do not support the East Asian monsoon as a major source of 437 moisture to the Plateau, given the lack of observed east-west $\delta^{18} \mathrm{O}$ gradients. 438 Pronounced east-west $\delta^{18} \mathrm{O}$ gradients are only observed in the eastern-most part of the 439 Plateau, suggesting this region as the limit of influence of the East Asian monsoon. $440 \quad \delta^{18} \mathrm{O}$ values show significant gradients in the south-north direction across the entire 441 Tibetan Plateau (Fig. 4C), suggesting the dominance of the South Asian monsoon and 442 Westerlies. This conclusion is supported by studies of atmospheric vapor flux across 443 all the margins of the Tibetan Plateau (Curio et al., 2015), and Lagrangian particle 444 dispersion modeling work (Chen et al., 2012), which suggest the main moisture flux 445 onto the Plateau comes from the south, west and north. 

central Plateau, Bershaw et al. (2012) show that in the southeast and east-central

448 Plateau, external moisture is mainly derived from the South Asian monsoon. In the 449 western Plateau, our back trajectory studies show that in the southern most site (Fig. $4508 \mathrm{~A})$, moisture is mainly derived from the South Asian monsoon (>70\%), whereas the 451 remaining $\sim 30 \%$ is from the north, transported by the Westerlies. Toward the north 452 and west (Fig. 8B-C), air masses from the South Asian monsoon decrease, and 453 moisture from the north increases. In the northern most site (Fig. 8D), Westerly 454 moisture dominates to account for about $70 \%$, whereas moisture from the South Asian 455 monsoon decreases to $\sim 30 \%$.
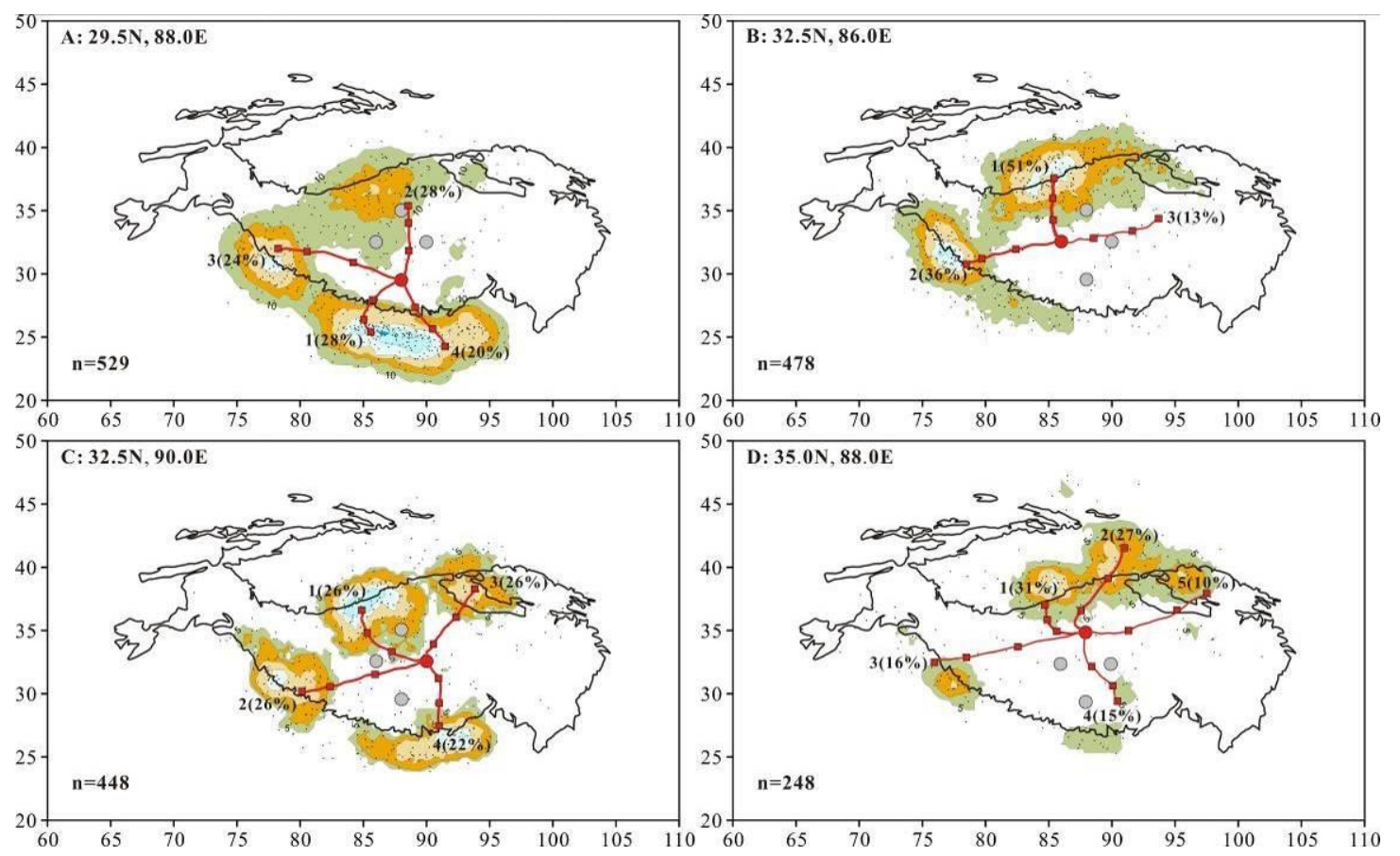

Fig. 8. HYSPLIT back trajectory end points of summertime (June, July, August; 2010-2013) air parcels (black dots) 72 hour prior to their arrival at one of the four selected locations in the western Plateau (big grey/red solid circles). The value of " $n$ " indicates the number of precipitation- producing trajectories. Color shades show spatial density of back trajectory end points. Red curves show clusters of back trajectories; red squares are locations for every 24 hours; the percentages indicate how many trajectories merged in this cluster. Black lines show the 3,000 m altitude contour of the Tibetan Plateau. 


\subsubsection{Surface water evaporation and recycling}

Although there are two major external moisture sources that influence the isotopic variations of meteoric waters on the Tibetan Plateau, a simple mixing of these two different moisture sources can not fully explain the spatial isotopic variations across the Tibetan Plateau (Bershaw et al., 2012). As shown in Fig. 4C, in the central plateau (between $30^{\circ} \mathrm{N}$ and $35^{\circ} \mathrm{N}$ ), the $\delta^{18} \mathrm{O}$ values are nearly the same at the same latitude. However, back trajectory analyses for locations at similar latitude in the western (Fig. 8B-C) and eastern Plateau (Bershaw et al., 2012) show various contributions of moisture from different sources. If mixing of these two external moisture sources were the dominant factor to control the isotopic variations, different $\delta^{18} \mathrm{O}$ values along lines of latitude, or more complex patterns, should be observed, which is not the case. In addition, the two moisture mixing model cannot account for the observed d-excess variations that show a large contrast between the eastern and western Plateau (Fig. 6B). Therefore, other factors must also contribute to the isotopic signals.

In continental settings, evaporation and transpiration of different surface waters (e.g., lake water, soil water and plant water) can be a significant contributor to atmospheric water vapor. A 12-year high-resolution climatology of the atmospheric vapor transport over and towards the Tibetan Plateau indicates that only $\sim 37 \%$ of the moisture required for precipitation on the Tibetan Plateau is derived from outside of the Plateau, which requires that $\sim 63 \%$ of moisture comes from local surface water evaporation and recycling (Curio et al., 2015). Stable isotopic studies of precipitation, near-surface atmospheric vapor and evapotranspiration in the central Plateau also indicate that locally recycled moisture plays an important role in contributing to precipitation (Kurita and Yamada, 2008). Based on these observations, Bershaw et al. 
(2012) used a surface water evaporation modified Rayleigh distillation model to

491 simulate the observed isotopic variations in surface waters and precipitation in the

511 also associated with smaller rainfall amount per precipitation event (e.g., Chen et al.,

512 2015; Peng et al., 2007). east-central Plateau.

\subsubsection{Sub-cloud evaporation as a significant controlling factor}

Neither mixing of different moisture sources nor addition of recycled surface water can account for the large difference in d-excess values between the eastern and western Plateau (Figure 5), as the second factor would lead to increase in d-excess values. Although lower condensation temperature can result in lower d-excess values, there is no observable difference in air temperature in the western compared to the eastern Plateau, during the summer time when most precipitation occurs (Maussion et al., 2014). There is also no difference in the seasonality of precipitation (Fig. 2) that could contribute to the east-west d-excess contrast. We propose that sub-cloud evaporation of raindrops might explain the anomalously low d-excess values in the western Plateau.

Raindrops falling through an unsaturated air column will partially evaporate, leading to enrichment of heavy isotopes in precipitation (increase $\delta^{18} \mathrm{O}$ and $\delta \mathrm{D}$ values; e.g., Lee and Fung, 2008). At the same time, kinetic fractionation due to low relative humidity will lead to more ${ }^{18} \mathrm{O}$ enrichment in the raindrop relative to ${ }^{2} \mathrm{H}$ (Gonfiantini, 1986), thus decreasing the d-excess values. Studies have shown that the intensity of sub-cloud evaporation increases with lower relative humidity and smaller raindrop radius (Lee and Fung, 2008), and that greater intensity of sub-cloud evaporation is$$
\text { 2015; Peng et al., 2007). }
$$

13 On the Tibetan Plateau, the amount of mean annual precipitation decreases from east $(>400 \mathrm{~mm})$ to west $(<200 \mathrm{~mm})$ (Fig. 9A). Available data suggests the 
515 rainfall amount per precipitation event is also higher in the east $(\sim 7.5 \mathrm{~mm}$; Tian et al., 516 2001) than in the west ( $5.0 \mathrm{~mm}$ in Gaize; Yu et al., 2007). We predict that smaller 517 rainfall amount (Fig. 9A) and lower mean relative humidity (Fig. 9B) in the western 518 Plateau would result in stronger sub-cloud evaporation (more fraction of raindrops 519 will be evaporated), leading to lower d-excess values of raindrops. In the eastern 520 Plateau, heavier rainfall that passes through a higher relative humidity air column 521 would reduce sub-cloud evaporation, and thus preserve higher d-excess values. 522 Similar observations (higher d-excess value - greater rainfall amount; lower d-excess 523 less rainfall) also exist in the southeastern Plateau, on the northern and southern side 524 of the Yarlung Tsangpo River (Fig. 6B, small box). The spatial correlation coefficient 525 between d-excess values with mean precipitation amount and relative humidity are 5260.44 and 0.40, respectively (Fig. 9C; both are significant above the 99\% confidence 527 level using the r-test), further supporting the correlations between d-excess values and 528 these two climate parameters. 

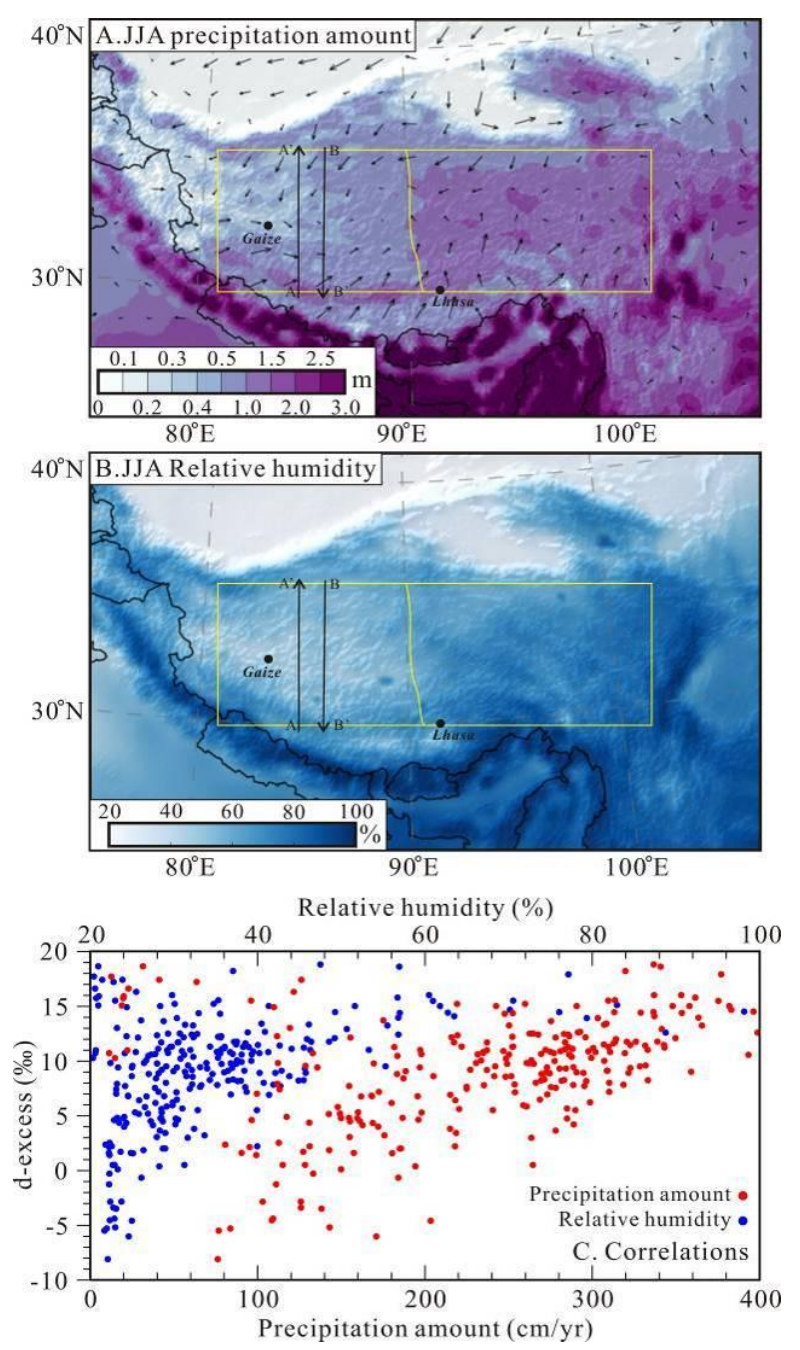

530 Fig. 9. Main rainy season (JJA: June, July, August for 2001-2013) precipitation amount (A) and 531 relative humidity (B) for the Tibetan Plateau area (Maussion et al., 2014). Black arrows in A are 532 wind direction and speed at $10 \mathrm{~m}$ above ground. Arrows A-A' and B-B' show simulated moisture 533 transport routes in the western Plateau. Yellow boxes show east/high vs. west/low contrasts. C, 534 correlations between d-excess values with annual mean relative humidity and precipitation amount.

We model the isotopic variations during sub-cloud evaporation within a modified Rayleigh distillation process to determine whether simulations provide a

538 match to observations in the western Tibetan Plateau. We consider two separate 539 simulations, following two generalized trajectories: A-A' and B-B' (Fig. 9A-B), 540 representing moisture transport from the South Asian monsoon and the Westerlies, 541 respectively (section 6.2.1) (see auxiliary appendix for method description and 542 auxiliary Table S4 for calculation spreadsheet). Our simulations show that along both 
543 of the two routes (A-A', from south to north; and B-B', from north to south), the

$544 \delta^{18} \mathrm{O}$ values decrease with progressive rainout (Fig. 10, open diamonds and squares).

545 However, after considering mixing of these two moisture sources (mixing ratios are

546 estimated from back trajectory analysis), the modeled $\delta^{18} \mathrm{O}$ values show a northward

547 increasing trend (Fig. 10, solid triangles). Along both of the routes, the d-excess

548 values first decrease and then increase (Fig. 10, plus signs and times signs), as a result

549 of the variations of the percentage of sub-cloud evaporation associated with variations

550 of relative humidity and rainfall amount (Fig. 9A-B). After mixing, the d-excess

551 values show lower values in the central and higher values in the northern and southern

552 ends (Fig. 10, solid circles). Both of the simulated $\delta^{18} \mathrm{O}$ and d-excess values follow

553 the observed variations in the western Plateau (Fig. 10, pink and green shaded areas).

554 These simulation attempts suggest that in the western Tibetan Plateau, the spatial

555 variations of $\delta^{18} \mathrm{O}$ and d-excess values result from at least two major factors: 1)

556 mixing of moisture from both the north (Westerlies) and south (South Asian monsoon)

557 and 2) sub-cloud evaporation.

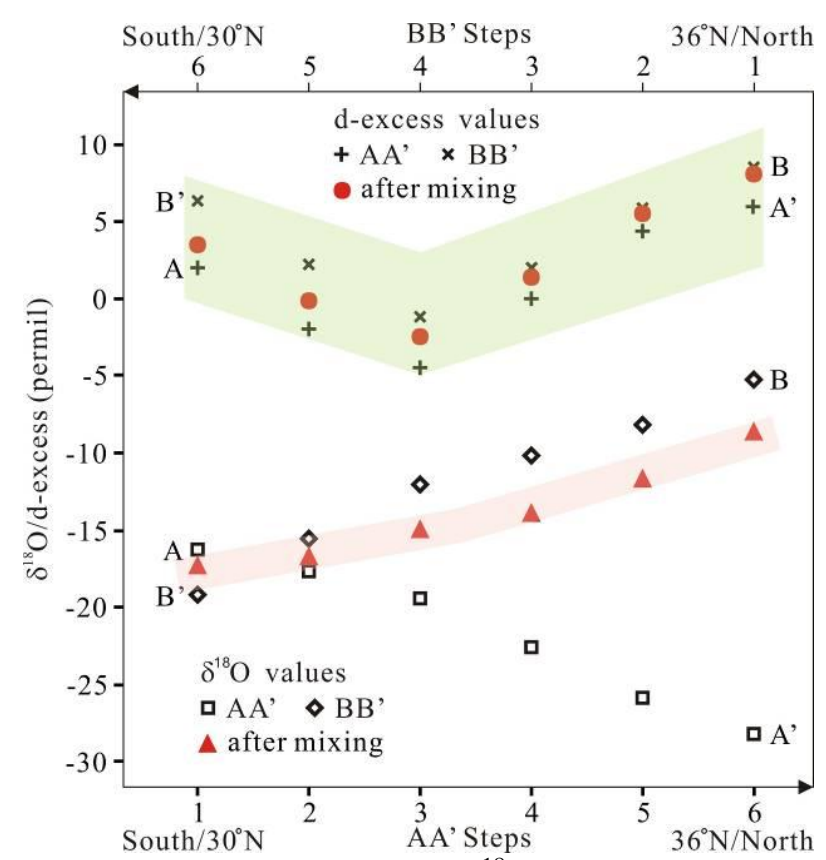

559 Fig. 10. Modeled isotopic variations (d-excess and $\delta^{18} \mathrm{O}$ values) of precipitation in two idealized 560 trajectories and their mixing in the western Tibetan Plateau: A-A', from south to north, moisture 
561 from the South Asian monsoon; B-B', from north to south, moisture from the Westerlies. The red

562 and green shaded areas outline observed $\delta^{18} \mathrm{O}$ and d-excess values between $30^{\circ} \mathrm{N}$ and $36^{\circ} \mathrm{N}$,

563 respectively. The mixing ratios (moisture from the south: moisture from the north) for each step

564 are estimated from back trajectory analysis and are (from south to north): 0.65:0.35, 055:0.45,

$565 \quad 0.40: 0.60,0.30: 0.70,0.20: 0.80,0.15: 0.85$.

Our simulations are simple and idealized, compared with the complex spatial variations of climatic parameters (relative humidity and rainfall amount) in the western Plateau (Fig. 9A-B). In addition, we did not consider the addition of recycled

570 local surface water, which has been shown to be important on the Tibetan Plateau 571 (Bershaw et al., 2012; Curio et al., 2015). The value of this modeling exercise is to 572 demonstrate that through a simplistic set of calculations, the variations in $\delta^{18} \mathrm{O}$ and d573 excess values in the western Tibetan Plateau can be accounted for by sub-could 574 evaporation of raindrops and moisture mixing; especially the anomalously low 575 d-excess values, which are difficult to produce by other atmospheric processes (e.g., 576 seasonality and condensation temperature).

577 Yet another process that might contribute to the low d-excess values in the 578 western Plateau is sublimation of snow. Similar to kinetic fractionation during 579 evaporation, sublimation can cause a decrease in the d-excess value of residual snow. 580 As a potentially important supply of river water and groundwater, the isotopic 581 composition of snowmelt could also influence river water composition. Although this 582 study cannot rule out the potential contribution of snowmelt to river water in the 583 western Tibetan Plateau, future studies focused on determining the isotopic 584 composition of surface snow and rainfall in the western Plateau region could resolve 585 the relative contributions of sublimation from snow versus sub-cloud evaporation 586 from raindrops. 


\section{Implications for stable isotope-based paleoaltimetry}

The application of stable isotope-based paleoaltimetry relies on assumptions that the isotopic evolution of rainfall follows equilibrium fractionation during

591 Rayleigh distillation of an ascending vapor mass to produce uncertainties that allow 592 for the detection of elevation changes (Rowley and Garzione, 2007; Rowley et al., 593 2001). Additional fractionation processes that vary strongly as a function of climate 594 aridity or extreme continentality (e.g., surface water recycling, sub-cloud evaporation, 595 and vapor mixing, etc.) result in uncertainties in stable isotope paleoaltimetry 596 estimates that are too large to apply these methods with confidence. Considering that 597 the observed systemic decreases in $\delta^{18} \mathrm{O}$ values with increasing elevation in the 598 southern through eastern margins of the Tibetan Plateau (Fig. 5A-B) can be 599 characterized by Rayleigh distillation (sections 6.1), we infer that stable isotope-based 600 paleoaltimetry is applicable in these regions. On the contrary, in the central-northern 601 Plateau (north of $30^{\circ} \mathrm{N}$ ), where isotopic compositions deviate from predictions of 602 Rayleigh distillation, as a result of the combined effects of mixing of different moisture sources, addition of recycled surface water and sub-cloud evaporation

604 (section 6.2), stable isotope-based paleoaltimetry cannot be applied without additional 605 constraints and/or large uncertainties.

606 Two methods have been proposed to solve this problem in the central-northern 607 Tibetan Plateau. The first method uses a different local isotope-altitude gradient (Ding 608 et al., 2009; Polissar et al., 2009; Xu et al., 2013), whereas the second method corrects 609 for the effect of latitudinal isotopic changes (Fig. 5E) (Bershaw et al., 2012; Quade et 610 al., 2011). Although both methods may be applicable under the same climate and 611 geography conditions as today, both methods suffer when applied to different 612 paleoclimate and paleogeographic conditions (Botsyun et al., 2016; Roe et al., 2016). 
613 For example, past differences in the position of India and the distribution of inland-

614 sea and topographic growth over the Cenozoic have resulted in significant changes in

615 the location of arid belts and high summertime precipitation (Roe et al., 2016). These

616 climatic and geographic differences result in significant changes in moisture sources,

617 recycling of surface water, and sub-cloud evaporation in different parts of the

618 (modern) plateau, leading to large deviations in the pattern of isotopes across this

619 region. Unless each of the processes can be constrained in the geologic past, the large

620 deviations from Rayleigh distillation isotopic patterns, as observed in the Tibetan

621 Plateau and Asian interior today, introduce large uncertainties in paleoaltimetry that 622 make this method inapplicable outside of regions that have adhered to a simple 623 Rayleigh distillation fractionation process.

624 These dilemmas signify the need to continue to develop new proxies for 625 paleoelevation that rely on different atmospheric parameters, such as temperature and 626 pressure, and to apply these multiple proxies where possible, although each with their 627 own limitations. In addition, continued work toward accurate characterization of 628 observations of both $\delta \mathrm{D}$ and $\delta^{18} \mathrm{O}$ in precipitation within general circulation models is 629 necessary to integrate both numerical simulation efforts and stable isotope-based 630 paleoaltimetry.

\section{$631 \quad$ 8. Summary}

632 To understand the controlling factors of modern surface water isotopic 633 variations and caveats to applying stable isotope-based paleoaltimetry in the Tibetan 634 Plateau, 1,340 modern surface water samples (458 newly collected) across a large 635 area of the Tibetan Plateau were compiled. By comparing river water $\delta^{18} \mathrm{O}$ values 636 with the amount-weighted mean annual oxygen isotopic values of precipitation, we 637 suggest that river water is a good substitute for isotopic studies of precipitation in the 
638 high flat interior of the Tibetan Plateau on the mean annual timescale. The isotopic 639 contour maps $\left(\delta^{18} \mathrm{O}, \delta \mathrm{D}\right.$ and d-excess) of modern surface waters on the Tibetan

640 Plateau can provide validation criteria for isotopic simulations using general 641 circulation models.

642 Different factors control the isotopic variations in different parts of the Tibetan 643 Plateau. For the marginal regions, in the windward parts of the southern (Himalaya), 644 southeastern (Yunnan Plateau) and eastern (Longmen Shan) margins, the decreasing $645 \delta^{18} \mathrm{O}$ values with increasing elevations can be modeled as a Rayleigh distillation 646 process, which suggests that stable isotope-based paleoaltimetry works well in the 647 southern through eastern margins of the Plateau. The interior of the Tibetan Plateau is 648 characterized by a northward increasing trend in $\delta^{18} \mathrm{O}$ values, and east (high)-west 649 (low) contrast in d-excess values. We conclude that these regional trends can be best 650 explained by the combined effects of three dominant processes: 1) different moisture 651 sources, 2) local surface water recycling, and 3) sub-cloud evaporation. Our modeling 652 of Rayleigh distillation including the effects of sub-cloud evaporation and moisture 653 mixing provides a means of reproducing the isotopic patterns in the western Tibetan 654 Plateau, including observed anomalously low d-excess values. These observations 655 indicate that in the interior of the Tibetan Plateau (north of $30^{\circ} \mathrm{N}$ ), where the $\delta^{18} \mathrm{O}$ 656 values of meteoric waters deviate from predictions of Rayleigh distillation, stable 657 isotope-based paleoaltimetry cannot be applied without additional constraints and/or 658 large uncertainties.

\section{Acknowledgments:}

661 We would like to thank Alex Pullen, Xiqiang Zhou, Martin Pepper, Xiangzhong 662 Li, Yi Jiang, Hong Chang, Jianghu Lan, Peng Zhang and Yun Li for their help 
663 collecting river water samples in the field; Penny Higgins for help in isotopic analysis;

664 Jeremy Caves for help with back trajectory analysis; Ran Feng for help with spatial

665 correlation analysis; and Yingying Jia for help with catchment mean elevation

666 calculation. This research was supported by the National Science Foundation grants

667 (EAR-0908778 and 1211527 to Garzione; EAR-1118525 and AGS-1203427 to Alex

668 Pullen) and National Science Foundation of China grant (40921120406 to Zhisheng

669 An), and a student grant from the Geological Society of America to Li. We are

670 grateful to Joel Saylor and two anonymous reviewers for thoughtful comments that

671 greatly improved the quality of the paper.

672

673

674 References

675 Araguás-Araguás, L., Froehlich, K., Rozanski, K., 1998. Stable isotope composition

676 of precipitation over southeast Asia. Journal of Geophysical Research 103, 2872167728742.

678 Bai, Y., Fang, X., Jia, G., Sun, J., Wen, R., Ye, Y., 2015. Different altitude effect of

679 leaf wax n-alkane $\delta \mathrm{D}$ values in surface soils along two vapor transport pathways,

680 southeastern Tibetan Plateau. Geochimica et Cosmochimica Acta 170, 94-107.

681 Bai, Y., Fang, X., Tian, Q., 2012. Spatial patterns of soil n-alkane $\delta D$ values on the

682 Tibetan Plateau: Implications for monsoon boundaries and paleoelevation 683 reconstructions. Journal of Geophysical Research 117, D20113, 684 doi:10.1029/2012JD017803.

685 Bershaw, J., Penny, S.M., Garzione, C.N., 2012. Stable isotopes of modern water 686 across the Himalaya and eastern Tibetan Plateau: Implications for estimates of 
paleoelevation and paleoclimate. Journal of Geophysical Research 117, D02110, doi:10.1029/2011JD016132.

689 Botsyun, S., Sepulchre, P., Risi, C., Donnadieu, Y., 2016. Impacts of Tibetan Plateau

690 uplift on atmospheric dynamics and associated precipitation $\delta^{18} \mathrm{O}$. Climate of the Past $691 \quad 12,1401-1420$.

692 Cerling, T.E., Quade, J., 1993. Stable carbon and oxygen isotopes in soil carbonates. 693 Geophysical Monograpy 78, 217-231.

694 Chamberlain, C.P., Poage, M., 2000. Reconstructing the paleotopography of mountain 695 belts from the isotopic composition of authigenic minerals. Geology 28, 115-118.

696 Chen, B., Xu, X.-D., Yang, S., Zhang, W., 2012. On the origin and destination of 697 atmospheric moisture and air mass over the Tibetan Plateau. Theoretical and applied 698 climatology 110, 423-435.

699 Chen, F.L., Zhang, M.J., Wang, S.J., Ma, Q., Zhu, X.F., Dong, L., 2015. Relationship 700 between sub-cloud secondary evaporation and stable isotopes in precipitation of 701 Lanzhou and surrounding area. Quaternary International 380-381, 68-74.

702 Craig, H., Gordon, L.I., 1965. Deuterium and oxygen 18 variations in the ocean and 703 the marine atmosphere, in: Tongiorgi, E. (Ed.), Stable isotopes in oceanographic 704 studies and paleotemperatures. Consiglio nazionale delle richerche, Laboratorio de 705 geologia nucleare, Spoleto, pp. 9-130.

706 Curio, J., Maussion, F., Scherer, D., 2015. A twelve-year high-resolution climatology 707 of atmospheric water transport over the Tibetan Plateau. Earth System Dynamics 6, 708 109-124.

709 Currie, B.S., Rowley, D.B., Tabor, N.J., 2005. Middle Miocene paleoaltimetry of 710 southern Tibet: Implications for the role of mantle thickening and delamination in the 711 Himalayan orogen. Geology 33, 181-184. 
712 Cyr, A.J., Currie, B.S., Rowley, D.B., 2005. Geochemical evaluation of Fenghuoshan

713 Group lacustrine carbonates, north-central Tibet: implications for the paleoaltimetry

714 of the Eocene Tibetan Plateau. Journal of Geology 113, 517-533.

715 Dansgaard, W., 1964. Stable isotopes in precipitation. Tellus 16, 436-468.

716 Ding, L., Xu, Q., Yue, Y.H., Wang, H.Q., Cai, F.L., Li, S., 2014. The Andean-type

717 Gangdese Mountains: Paleoelevation record from the Paleocene-Eocene Linzhou 718 Basin. Earth and Planetary Science Letters 392, 250-264.

719 Ding, L., Xu, Q., Zhang, L.Y., Yang, D., Lai, Q.Z., Huang, F.X., Shi, R.D., 2009.

720 Regional variation of river water oxygen isotope and empirical elevation prediction 721 models in Tibetan Plateau. Quaternary Sciences 29, 1-12 (in Chinese with English 722 abstract).

723 Draxler, R.R., Rolph, G.D., 2013. HYSPLIT (HYbrid Single-Particle Lagrangian 724 Integrated Trajectory) Model access via NOAA ARL READY Website 725 (http://ready.arl.noaa.gov/HYSPLIT.php). NOAA Air Resources Laboratory, Silver 726 Spring, MD.

727 Feng, L., Zhou, T., 2012. Water vapor transport for summer precipitation over the 728 Tibetan Plateau: Multidata set analysis. Journal of Geophysical Research: 729 Atmospheres 117, D20, doi:10.1029/2011JD017012.

730 Froehlich, K., Kralik, M., Papesch, W., Rank, D., Scheifinger, H., Stichler, W., 2008.

731 Deuterium excess in precipitation of Alpine regions-moisture recycling. Isotopes in 732 environmental and health studies 44, 61-70.

733 Garzione, C.N., Dettman, D.L., Horton, B.K., 2004. Carbonate oxygen isotope 734 paleoaltimetry: evaluating the effect of diagenesis on paleoelevation estimates for the 735 Tibetan plateau. Palaeogeography, Palaeoclimatology, Palaeoecology 212, 119-140. 
736 Garzione, C.N., Dettman, D.L., Quade, J., DeCelles, P.G., Butler, R.F., 2000a. High

737 times on the Tibetan Plateau: Paleoelevation of the Thakkhola graben, Nepal.

738 Geology 28, 339-342.

739 Garzione, C.N., Quade, J., DeCelles, P.G., English, N.B., 2000b. Predicting 740 paleoelevation of Tibet and the Himalaya from $\delta^{18} \mathrm{O}$ vs. altitude gradients in meteoric 741 water across the Nepal Himalaya. Earth and Planetary Science Letters 183, 215-229.

742 Gonfiantini, R., 1986. Environmental isotopes in lake studies, in: Fritz, P., Fontes, J.C.

743 (Eds.), Handbook of environmental isotope geochemistry. Elsevier, New York, pp. $744 \quad 113-168$.

745 Gonfiantini, R., Roche, M.-A., Olivry, J.-C., Fontes, J.-C., Zuppi, G.M., 2001. The 746 altitude effect on the isotopic composition of tropical rains. Chemical Geology 181, $747 \quad 147-167$.

748 Hoke, G.D., Garzione, C.N., Araneo, D.C., Latorre, C., Strecker, M.R., Williams, K.J., 749 2009. The stable isotope altimeter: Do Quaternary pedogenic carbonates predict 750 modern elevations? Geology 37, 1015-1018.

751 Hoke, G.D., Liu-Zeng, J., Hren, M., Wissink, G.K., Garzione, C.N., 2014. Stable 752 isotopes reveal high southeast Tibetan Plateau margin since the Paleogene. Earth and 753 Planetary Science Letters 394, 270-278.

754 Hren, M.T., Bookhagen, B., Blisniuk, P.M., Booth, A.L., Chamberlain, C.P., 2009. $755 \delta^{18} \mathrm{O}$ and $\delta \mathrm{D}$ of streamwaters across the Himalaya and Tibetan Plateau: Implications 756 for moisture sources and paleoelevation reconstructions. Earth and Planetary Science 757 Letters 288, 20-32.

758 Huntington, K.W., Saylor, J., Quade, J., Hudson, A.M., 2014. High late Miocene759 Pliocene elevation of the Zhada Basin, southwestern Tibetan Plateau, from carbonate 760 clumped isotope thermometry. Geological Society of America Bulletin 127, 181-199. 
761 Jouzel, J., Merlivat, L., 1984. Deuterium and oxygen 18 in precipitation: modeling of

762 the isotopic effects during snow formation. Journal of Geophysical Research 89, 763 11749-11757.

764 Kanamitsu, M., Ebisuzaki, W., Woollen, J., Yang, S.-K., Hnilo, J., Fiorino, M., Potter, 765 G., 2002. NCEP-DOE AMIP-II Reanalysis (R-2). Bulletin of the American 766 Meteorological Society 83, 1631-1643.

767 Kendall, C., Coplen, T.B., 2001. Distribution of oxygen-18 and deuterium in river 768 waters across the United States. Hydrological processes 15, 1363-1393.

769 Kurita, N., Yamada, H., 2008. The role of local moisture recycling evaluated using 770 stable isotope data from over the middle of the Tibetan Plateau during the monsoon 771 season. Journal of Hydrometeorology 9, 760-775.

772 Lee, J.E., Fung, I., 2008. "Amount effect" of water isotopes and quantitative analysis 773 of post-condensation processes. Hydrological processes 22, 1-8.

774 Liu, Q., 2014. Variations of river water stable isotopes on the Tibetan Plaeau and 775 adjacent regions [M.S. thesis]. Southwest University, Chongqing, p. 59.

776 Liu, Q., Tian, L.D., Wang, J.L., Wen, R., Weng, Y.B., Shen, Y.P., Vladislav, M., 777 Kanaev, E., 2014. A study of longitudinal and altitudinal variations in surface water 778 stable isotopes in West Pamir, Tajikistan. Atmospheric Research 153, 10-18.

779 Maussion, F., Scherer, D., Mölg, T., Collier, E., Curio, J., Finkelnburg, R., 2014. 780 Precipitation Seasonality and Variability over the Tibetan Plateau as Resolved by the 781 High Asia Reanalysis. Journal of Climate 27, 1910-1927.

782 Merlivat, L., Jouzel, J., 1979. Global climatic interpretation of the deuterium-oxygen 78318 relationship for precipitation. Journal of Geophysical Research 84, 5029-5033. 
784 Peng, H., Mayer, B., Harris, S., Krouse, H., 2007. The influence of below-cloud 785 secondary effects on the stable isotope composition of hydrogen and oxygen in 786 precipitation at Calgary, Alberta, Canada. Tellus B 59, 698-704.

787 Poage, M.A., Chamberlain, C.P., 2001. Empirical relationships between elevation and 788 the stable isotope composition of precipitation and surface waters: considerations for 789 studies of paleoelevation change. American Journal of Science 301, 1-15.

790 Polissar, P.J., Freeman, K.H., Rowley, D.B., McInerney, F.A., Currie, B.S., 2009.

791 Paleoaltimetry of the Tibetan Plateau from D/H ratios of lipid biomarkers. Earth and 792 Planetary Science Letters 287, 64-76.

793 Quade, J., Breecker, D.O., Daeron, M., Eiler, J., 2011. The paleoaltimetry of Tibet: 794 An isotopic perspective. American Journal of Science 311, 77-115.

795 Roe, G.H., Ding, Q., Battisti, D.S., Molnar, P., Clark, M.K., Garzione, C.N., 2016. A 796 modeling study of the response of Asian summertime climate to the largest geologic 797 forcings of the past 50 Ma. Journal of Geophysical Research: Atmospheres doi: 798 10.1002/2015JD024370.

799 Rowley, D.B., Garzione, C.N., 2007. Stable isotope-based paleoaltimetry. Annual 800 Review of Earth and Planetary Sciences 35, 463-508.

801 Rowley, D.B., Pierrehumbert, R.T., Currie, B.S., 2001. A new approach to stable 802 isotope-based paleoaltimetry: implications for paleoaltimetry and paleohypsometry of 803 the High Himalaya since the Late Miocene. Earth and Planetary Science Letters 188, $804 \quad 253-268$.

805 Rozanski, K., Araguás-Araguás, L., Gonfiantini, R., 1993. Isotopic patterns in modern 806 global precipitation. Geophysical Monograph Series 78, 1-36. 
807 Saylor, J., Quade, J., Dettman, D., DeCelles, P., Kapp, P., Ding, L., 2009. The late

808 Miocene through present paleoelevation history of southwestern Tibet. American 809 Journal of Science 309, 1-42.

810 Spicer, R.A., Harris, N.B.W., Widdowson, M., Herman, A.B., Guo, S., Valdes, P.J., 811 Wolfe, J.A., Kelley, S.P., 2003. Constant elevation of southern Tibet over the past 15 812 million years. Nature 421, 622-624.

813 Talbot, M.R., 1990. A review of the palaeohydrological interpretation of carbon and 814 oxygen isotopic ratios in primary lacustrine carbonates. Chemical Geology: Isotope 815 Geoscience Section 80, 261-279.

816 Tian, L.D., Masson-Delmotte, V., Stievenard, M., Yao, T., Jouzel, J., 2001. Tibetan 817 Plateau summer monsoon northward extent revealed by measurements of water stable 818 isotopes. Journal of Geophysical Research 106, 28081-28088.

819 Tian, L.D., Yao, T.D., MacClune, K., White, J.W.C., Schilla, A., Vaughn, B., Vachon, 820 R., Ichiyanagi, K., 2007. Stable isotopic variations in west China: A consideration of 821 moisture sources. Journal of Geophysical Research 112, D10112, 822 doi:10.1029/2006JD007718.

823 Xu, Q., Ding, L., Zhang, L.Y., Cai, F.L., Lai, Q.Z., Yang, D., Liu-Zeng, J., 2013. 824 Paleogene high elevations in the Qiangtang Terrane, central Tibetan Plateau. Earth 825 and Planetary Science Letters 362, 31-42.

826 Xu, Q., Hoke, G.D., Liu-Zeng, J., Ding, L., Wang, W., Yang, Y., 2014. Stable 827 isotopes of surface water across the Longmenshan margin of the eastern Tibetan 828 Plateau. Geochem. Geophys. Geosyst 15, doi:10.1002/2014GC005252.

829 Yao, T.D., Masson-Delmotte, V., Gao, J., Yu, W.S., Yang, X.X., Risi, C., Sturm, C., 830 Werner, M., Zhao, H.B., He, Y., Ren, W., Tian, L.D., Shi, C.M., Hou, S.G., 2013. A 
831 Review of climatic controls on $\delta^{18} \mathrm{O}$ in precipitation over the Tibetan Plateau:

832 observations and simulations. Reviews of Geophysics 51, 525-548.

833 Yu, W.S., Yao, T.D., Tian, L.D., Ma, Y.M., Kurita, N., Ichiyanagi, K., Wang, Y., Sun,

834 W.Z., 2007. Stable isotope variations in precipitation and moisture trajectories on the

835 western Tibetan Plateau, China. Arctic, Antarctic, and Alpine Research 39, 688-693.

836

837

838 